\title{
Integrated Stage Dual Buck -Boost Fly Back Converter LED Driver
}

\author{
Kannan Subha Sharmini ${ }^{1 *}$, Prateek Gulati ${ }^{2}$, Ankit Jain ${ }^{3}$ \\ ${ }^{I}$ Prof-EEE, SRM IST-Chennai, India \\ ${ }^{2} B$ Tech-EEE, SRM IST - Chennai, India \\ ${ }^{3} B$ Tech-EEE, SRM IST - Chennai, India \\ *Corresponding author E-mail *subha.a.star@gmail.com
}

\begin{abstract}
This paper presents a novel integrated stage converter configuration being applied as a LED driver. In order to prove the betterment of the topology, its performance is compared in terms of power factor, output voltage and settling time with three other randomly selected topologies: A single switch AC-DC LED driver based on boost fly back power factor correction converter with a lossless snubber, Integrated stage double buck- boost converter LED driver, Integrated stage LED driver based on buck-boost and class E resonant converter. As a consequence of relevant simulations of all the chosen topologies with resistance as the load, it is understood that Integrated buck boost fly back converter based LED Driver is beneficial as a compromise between all circuits. Hence the same is translated into an experimental prototype which is capable of a yield rated $45 \mathrm{~V}, 84.6 \mathrm{~W}$ and $1.88 \mathrm{~A}$ for a LED string load.
\end{abstract}

Keywords: Buck; Boost; Driver; Integrated Stage; Fly back; Light emitting diode.

\section{Introduction}

This document details the working performance- characteristic features of an integrated stage double buck- boost fly back converter LED driver. LED lighting systems are probable to become the most used in the coming years because of the vast number of advantages offered by them which are as listed below:

- Humongous saving of energy compared to conventional lighting systems.

- Durability and quicker response.

- $\quad$ Eco - friendliness....

LED drivers are generally circuits that are used to provide constant current to a LED string load regardless of its varying electrical characteristics. LED drivers can be of single stage, dual stage or integrated stage structure [1] as shown in Fig.1. It also becomes necessary to include power factor correction (PFC) module to increase input power factor to reduce harmonics as available power supply in most cases is AC $230 \mathrm{~V}, 50 \mathrm{~Hz}$.

A single stage LED driver makes use of any DC- DC converter to give constant current, but it requires a large value of capacitor for PFC, which becomes its drawback.

A two stage topology has a separate converter circuit for PFC and DC - DC converter and this adds to the volume/cost of the driver as number of devices and other passive elements are almost doubled. In an integrated stage configuration PFC and DC - DC converter stages share a common switch and control circuitry. This arrangement greatly reduces the size, expense and also results in considerably higher efficiency, reliability and fast output dynamics [1]

As part of this article an integrated stage LED driver with a dual buck - boost topology at its front end and a fly back converter at its back end is proposed. The control switch is one in number and is common to both buck boost stages \& fly back stages, which is an added credit.

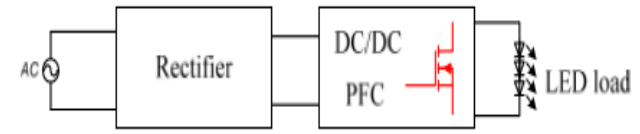

(a) Single-stage

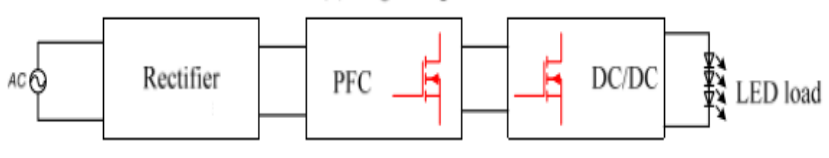

(b) Two-stage

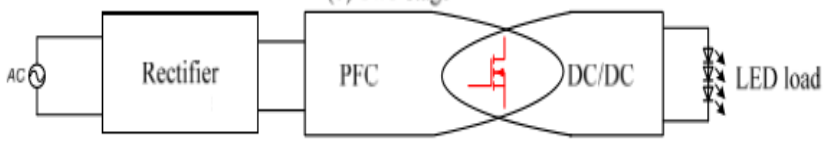

(c) Integrated-stage

Fig. 1: Structure of LED drivers [1]

\section{Converter topologies for LED driver}

Many versions of DC-DC converters have been developed or are under development all these years viz. buck, boost, buck-boost, zeta, SEPIC etc...The focus of this article is to hand pick few such configurations from recent research papers over the past decade and do a comparative analysis and find the best choice for the hardware prototype design of LED driver. A brief description of the chosen circuits is given below: 


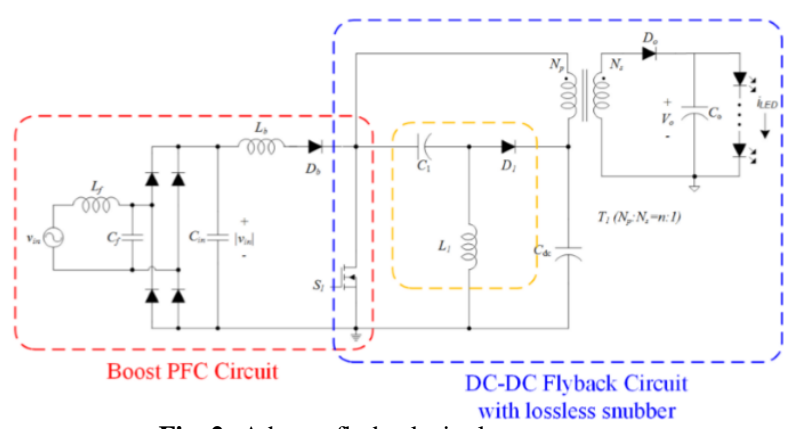

Fig. 2: A boost fly back single stage converte

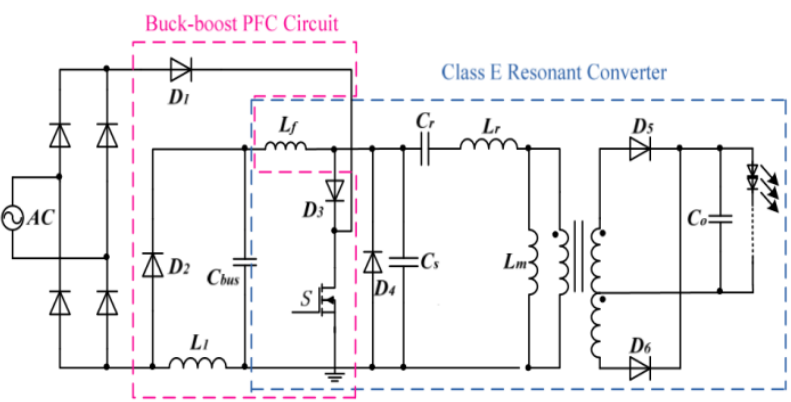

Fig. 3: Integrated buck - boost with class E resonant converter

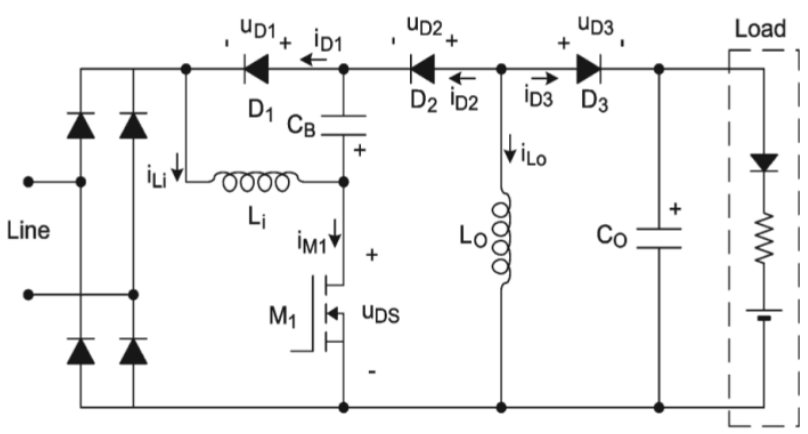

Fig. 4: Integrated stage dual buck - boost converter

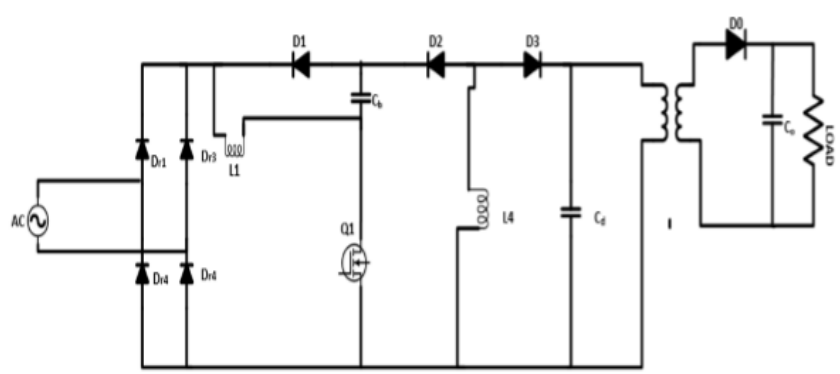

Fig. 5 Integrated stage dual buck - boost with fly back converter

\subsection{A boost fly back PFC single stage converter}

The circuit (Fig. 2) has a boost converter, which when operated in discontinuous conduction mode can do power factor correction. Effective electrical isolation is obtained with the aid of the fly back converter module constituting a snubber circuit diode and a capacitor.

\subsection{Integrated stage buck - boost with class $\mathbf{E}$ resonant converter}

Integrated stage converter can also be used with LLC resonant converter or class E resonant converter (Fig. 3) at its load end. In comparison with LLC based IDBB, class E resonant converter has a simple structure because of its lone active switch. But increased device stress restricts its application as a LED driver.

\section{Integrated Stage Dual Buck - Boost with Fly Back Converter}

As this circuit (Fig. 5) is of integrated stage, the buck boost converter cascaded 2 in number, share control switch. The other passive elements include two nos. of inductors and capacitors. The back end stage/ load stage is the fly back transformer with lossless snubber. When the dual buck boost stage is operated in DCM, the values of line current and voltage will be proportional resulting in near unity PF. The presence of the fly back converter in the output section leads to the output voltage rectification and filtering and necessary electrical isolation.

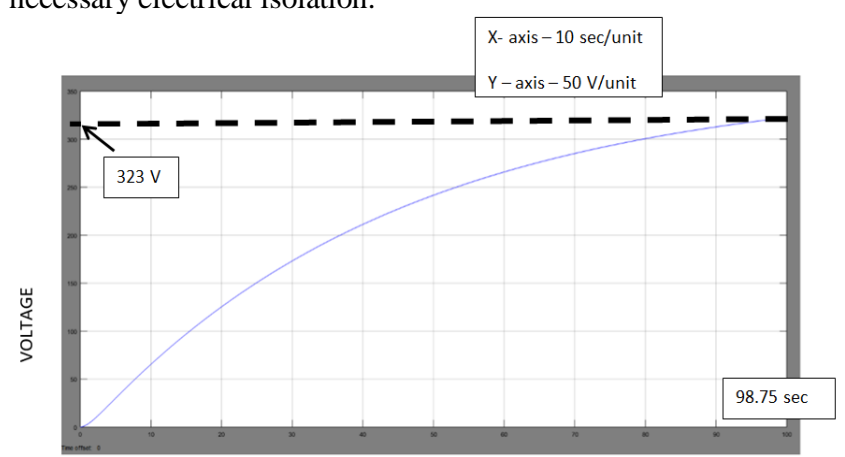

Fig. 6: DC bus voltage - Single stage boost fly back converter with lossless snubber

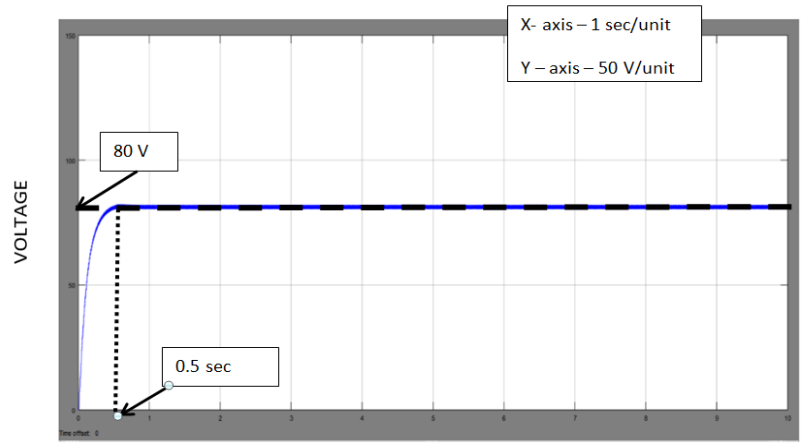

Fig. 7: DC bus voltage - Integrated stage buck -boost with class E resonant converter

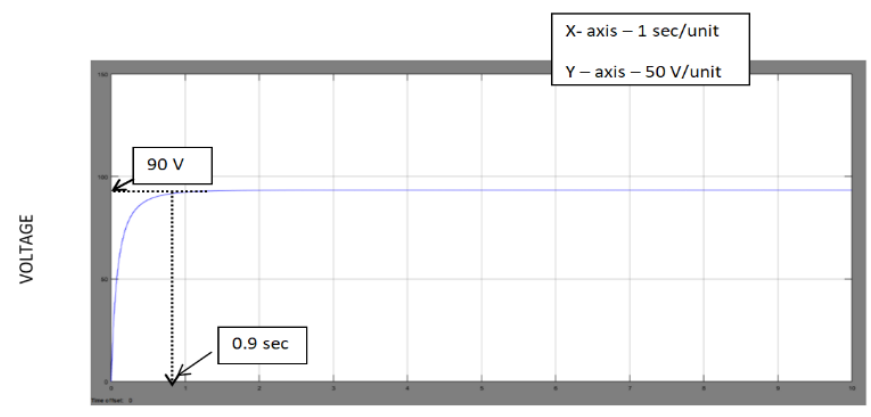

Fig. 8: DC bus voltage - IDBB

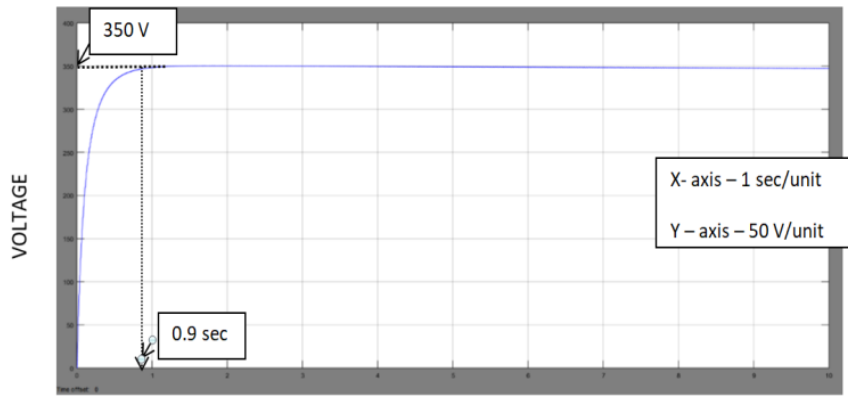

Fig. 9: Integrated stage dual buck - boost with fly back converter 

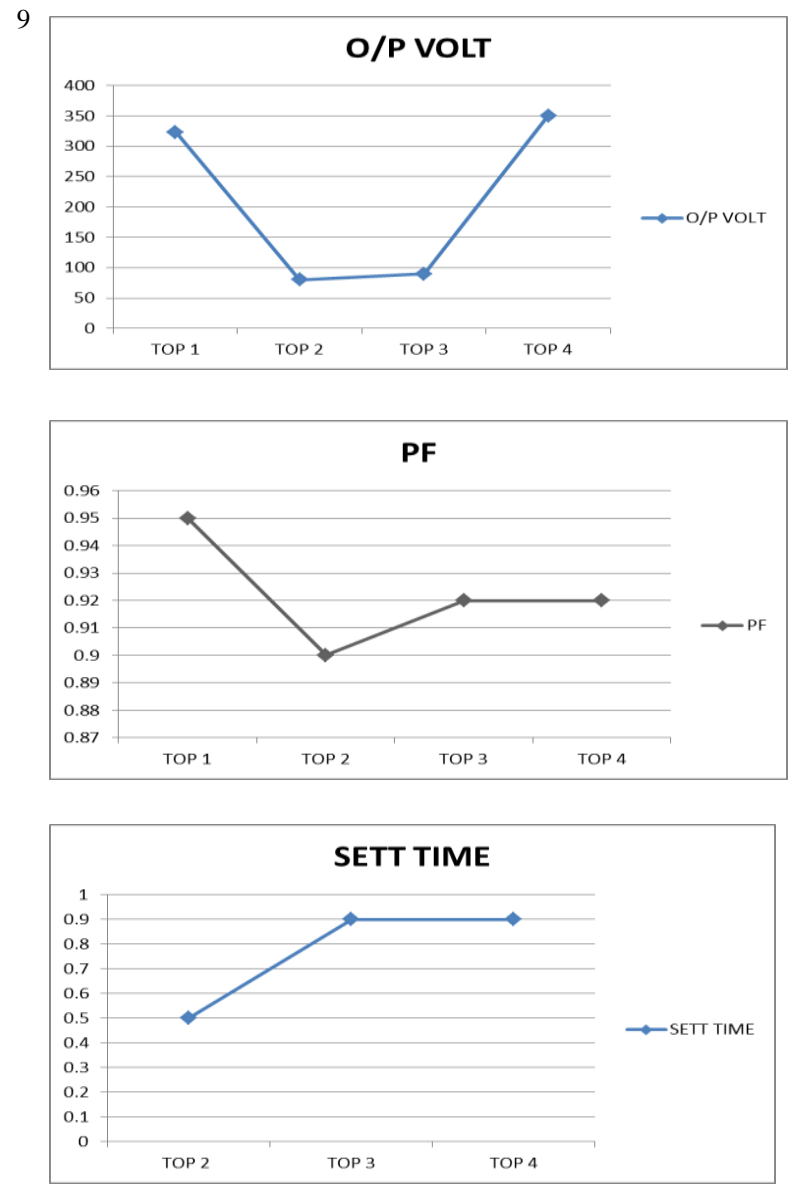

- TOP 1 - A single stage boost fly back converter

- TOP 2 - An integrated stage buck - boost class E resonant converter

- TOP 3 - IDBB

- $\quad$ TOP 4 - IDBB with flyback converter

Fig. 10: Comparative analysis of the chosen topologies.

Table 1: Hardware design parameters

\begin{tabular}{|c|c|}
\hline Components & Specification \\
\hline MOSFET & IRF840 \\
Capacitor & $10 \mu \mathrm{F}, 470 \mu \mathrm{F}$ \\
Volt Regulator & LM7805 \\
Crystal Oscillator & $1-\quad 20 \mathrm{MHz}$ \\
Diode & IN4007 \\
Resistor & $110 \mathrm{~K} \Omega$ \\
Inductor & $100 \mathrm{mH}, 100$ turns \\
Transformer & $230 \mathrm{~V} / 12 \mathrm{~V}$ \\
Driver IC & TLP250 \\
LED Load & $1 \mathrm{~W}, 3.3$ to $4 \mathrm{~V}$ \\
\hline
\end{tabular}

\section{Small Scale Prototype}

A prototype of the proposed design for LED dimmer load is developed. It consists of four blocks: Controller, Driver, Converter and LED load. The AC source voltage of $230 \mathrm{~V}, 50 \mathrm{~Hz}$ is stepped down to $12 \mathrm{~V}$ AC. The rectification action follows up resulting in a pulsating DC. The ripple is eliminated by a capacitor filter. DSPIC30F2010 is operated on MPLAB IDE and dumped with hex file for pulse generation of the control switch. The gating pulse thus generated is fed through an opto- coupler. This cascaded dual buck boost converter stage forms the primary of the fly back isolation driving the dimmer load. Two states of lighting variation can be obtained by a variable resistor.

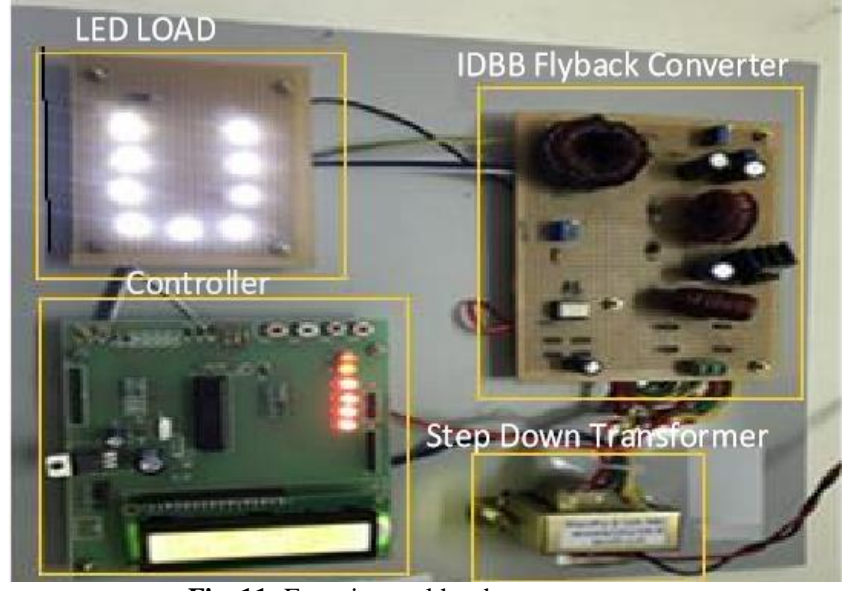

Fig. 11: Experimental hardware prototype.

\section{Conclusion}

In this paper a novel LED driver with a fly back converter at its end stage is proposed. As the proposed topology seems to perform better when compared to the single stage boost fly back converter and integrated stage buck boost topology with class E resonant converter in terms of power factor and the time response, the same circuit is implemented as an experimental prototype thereby validating the simulation results.

\section{Acknowledgement}

The authors are thankful to their department colleagues for their constant help and encouragement.

\section{References}

[1] Yijie Wang, J. Marcos Alonso and Xinbo Ruan,” A review of LED drivers and related technologies", IEEE Transactions on Industrial Electronics, Vol.X, No.X, (200X), pp.XX-XX, accepted for publiccation.

[2] Marcos Alonso, Juan Viña, David Gacio Vaquero, Gilberto Martínez, and René Osorio," Analysis and design of the integrated double buck boost converter as a high power factor driver for power - LED lamps", IEEE Transactions on Industrial Electronics, Vol.59, No.4, (2012), pp.1689-1697.

[3] K.I.Hwu, Y.T.Yau and L.-L.Lee,” Powering LED using highefficiency SR fly back converter", Proceedings of the 24th annual IEEE APEC conference, (2009).

[4] D. Gacio, J. M. Alonso, A. J. Calleja, J. Garcia, and M. RicoSecades," A universal-input single-stage high-power-factor power supply for HB-LEDs based on integrated buck-fly back converter ", IEEE Transactions on Industrial Electronics, Vol.58, No.2, (2011), pp.1589-599.

[5] Q. Hu and R. Zane," LED driver circuit with series-inputconnected converter cells operating in continuous conduction mode", IEEE Transactions on Industrial Electronics, Vol.25, No.3, (2010), pp.574-582.

[6] T.-J. Liang, C.-M. Huang and J.-F. Chen," Two-stage highpower-factor electronic ballast for metal-halide lamps", IEEE Transactions on Industrial Electronics, Vol.24, No.12, (2009), pp.2959-2966.

[7] M H Rashid, Power Electronics Handbook, Elsevier, (2007).

[8] H.-Y. Li, H.-C. Chen," Dynamic modeling and controller design for a single-stage single-switch parallel boost-fly backfly back converter", IEEE Transactions on Power Electronics, Vol.27, No.2, (2012), pp.816-827.

[9] X. Wu, J. Yang, J. Zhang, Z. Qian,” Variable on-time (VOT) controlled critical conduction mode buck PFC converter for high-input AC-DC HB-LED lighting applications", IEEE Transactions on Power Electronics, Vol.27, No.11, (2012), pp.4530-4531.

[10] Y. Wang, Y. Guan, D. Xu, W. Wang," A CLCL resonant DC/DC converter for two-stage LED driver system", IEEE 
Transactions on Industrial Electronics, Vol.63, No.5, (2014), pp.2883-2886.

[11] J. Shao," Single stage offline LED driver", Proceedings of the 24th annual IEEE APEC conference, (2009). , pp.582-586

[12] Y. Wang, J. Huang, W. Wang, D. Guo," A single-stage single-Switch LED driver based on class-E converter", IEEE Transactions on Industrial Applications, Vol.52, No.3, (2016), pp. 2618-2620

[13] Y. Wang, Y. Guan, K. Ren, W. Wang, D. Xu," A single-stage LED driver based on BCM boost circuit and LLC Converter for street lighting system ", IEEE Transactions on Industrial Electronics, Vol.62, No.9, (2015), pp. 5446-5448.

[14] E F Schubert, Light - Emitting Diodes, 2nd Edition, Cambridge University Press, (2006).

[15] Cree X Lamp XP - C LEDs, 2010, Data Sheet. CLD - DS19, Rev 4

[16] S. Y. R. Hui, S. N. Li, X. H. Tao, W. Chen, and W. M. Ng, "A novel passive off-line light-emitting diode (LED) driver with long lifetime," , IEEE Transactions on Power Electronics, Vol.25, No.10, (2010), pp. 2665-2672.

[17] Z. Ye, F. Greenfeld, and Z. Liang," Single-stage offline SEPIC converter with power factor correction to drive high brightnessLEDs," Proceedings of the 24th annual IEEE APEC conference, (2009). pp. 546-553. 